\title{
An air-stable bisboron complex: a practical bidentate Lewis acid catalyst
}

\author{
Longcheng Hong ${ }^{1}$, Sebastian Ahles ${ }^{1}$, Andreas H. Heindl ${ }^{1}$, Gastelle Tiétcha ${ }^{1}$, \\ Andrey Petrov ${ }^{1}$, Zhenpin Lu ${ }^{1,2}$, Christian Logemann ${ }^{3}$ and Hermann A. Wegner ${ }^{* 1}$
}

\author{
Full Research Paper \\ Address: \\ ${ }^{1}$ Institute of Organic Chemistry, Justus Liebig University Giessen, \\ Heinrich-Buff-Ring 17, 35392 Giessen, Germany, ${ }^{2}$ Current position: \\ Department of Chemistry, University of Cambridge, Lensfield Road, \\ Cambridge CB2 1EW, United Kingdom and ${ }^{3}$ Institute of Inorganic \\ Chemistry, University of Cologne, Greinstr. 4, 50939 Cologne, \\ Germany \\ Email: \\ Hermann A. Wegner* - \\ Hermann.A.Wegner@org.Chemie.uni-giessen.de \\ * Corresponding author \\ Keywords: \\ air-stable catalyst; bidentate; bisboron; diazine; Diels-Alder; Lewis \\ acid \\ Beilstein J. Org. Chem. 2018, 14, 618-625. \\ doi:10.3762/bjoc. 14.48 \\ Received: 22 December 2017 \\ Accepted: 20 February 2018 \\ Published: 13 March 2018 \\ Associate Editor: B. Stoltz \\ (c) 2018 Hong et al.; licensee Beilstein-Institut. \\ License and terms: see end of document.
}

\begin{abstract}
We report an air-stable bisboron complex as an efficient catalyst for the inverse electron-demand Diels-Alder (IEDDA) reaction of 1,2-diazine as well as 1,2,4,5-tetrazine. Its stability towards air and moisture was demonstrated by NMR studies enabling its application in organic transformations without glovebox. A one-pot procedure for its synthesis was developed starting from 1,2-bis(trimethylsilyl)benzene greatly enhancing its practicality. Comparative reactions were carried out to evaluate its catalytic activity in IEDDA reactions of diazine including phthalazine as well as 1,2,4,5-tetrazine.
\end{abstract}

\section{Introduction}

The development of efficient and practical methods for synthesis is one of the prime objectives in chemistry. Especially transformations relying on new catalytic activation principles are of importance. In the past years, the inverse electron-demand Diels-Alder (IEDDA) reaction has been well established for the construction of cyclic frameworks, especially in the synthesis of natural products $[1,2]$. Aza-dienes have been utilized in IEDDA reactions for the construction of nitrogen-containing hetero- cyclic compounds [3-8]. Among them, 1,2-diazines are less used owing to their relative low reactivity as their LUMOs are rather high in energy [9-12]. In the past years, we demonstrated a bisboron bidentate Lewis acid (Scheme 1, A) as an efficient catalyst for the IEDDA reaction of 1,2-diazines to access 1,2substituted aromatics $[13,14]$. Additionally, we could incorporate this reactivity in domino reactions combining the IEDDA step with rearrangements [15] or additional Diels-Alder reac- 
tions [16]. However, the methodology requires an air and moisture-sensitive bisboron catalyst. The preparation as well as the handling requires special equipment such as a glovebox, therefore, restricting its applicability [17]. To overcome this limitation we herein present a new catalyst (Scheme 1, B) with reasonable stability to air and moisture, which can be handled under ambient conditions and prepared with standard laboratory equipment.<smiles>CB1c2ccccc2B(C)c2ccccc21</smiles>

A: bidentate Lewis acid

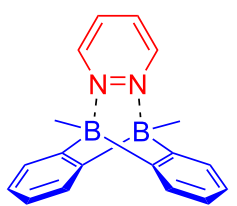

B: air-stable bisborane complex
Scheme 1: Bidentate bisborane Lewis acids.

\section{Results and Discussion}

Generally, the reactivity of boron Lewis acids is attributed to the free vacant p-orbital of the boron atom leading to further transformations, such as decomposition via radicals $\left(\mathrm{O}_{2}\right)$, reactions with nucleophiles $\left(\mathrm{H}_{2} \mathrm{O}\right)$ as well as the formations of adducts. From this perspective, a suitable Lewis base may form a Lewis complex and subsequently occupy the p-orbital of the boron atom. This may prevent the boron compound from decomposition as well as hydrolysis and provide a practical Lewis acid catalyst for organic reactions.
To test the hypothesis, several Lewis bases were subjected to the coordination reaction with the bidentate bisboron catalyst, 5,10-dimethyl-5,10-dihydroboranthrene (A in Scheme 1), developed in our group [13]. A complexation was confirmed by a high field shift of the aromatic protons compared with the noncoordinated catalyst A. As shown in Scheme 2, besides 1,2diphenylhydrazine (1d), most of the Lewis bases including monodentate $\mathbf{1 a}-\mathbf{1 c}$ and bidentate Lewis bases $\mathbf{1 e}-\mathbf{1 j}$ can coordinate with bisboron compound $\mathbf{A}$ as determined by NMR spectroscopy (see Supporting Information File 1). The stability was then evaluated exposing the resulting complexes to air. However, most adducts quickly decomposed under ambient conditions except the adduct $\mathbf{B}$ of pyridazine (1j). To further evaluate the stability of complex B, a time-dependent ${ }^{1} \mathrm{H}$ NMR study was conducted. The first signs of decomposition appeared in the low field regions of the ${ }^{1} \mathrm{H}$ NMR spectrum after 17 days (Figure 1c). These decomposition signals increased with ongoing air exposure (Figure 1c-1e). Nevertheless, there was a significant amount of complex B remaining even after 38 days of air exposure (Figure 1e).

\section{Optimized procedure for the synthesis of complex B}

The synthesis of bisboron compound $\mathbf{A}$ has been well described by Wagner's group [18] as well as by our group [17]. A typical procedure for the synthesis of bisboron compound $\mathbf{A}$ via a dimerization requires a high reaction temperature (Scheme 3, top). Due to the use of volatile $\mathrm{BCl}_{3}$, the dimerization reaction is usually carried out in a sealed pressure tube. Using Schlenk

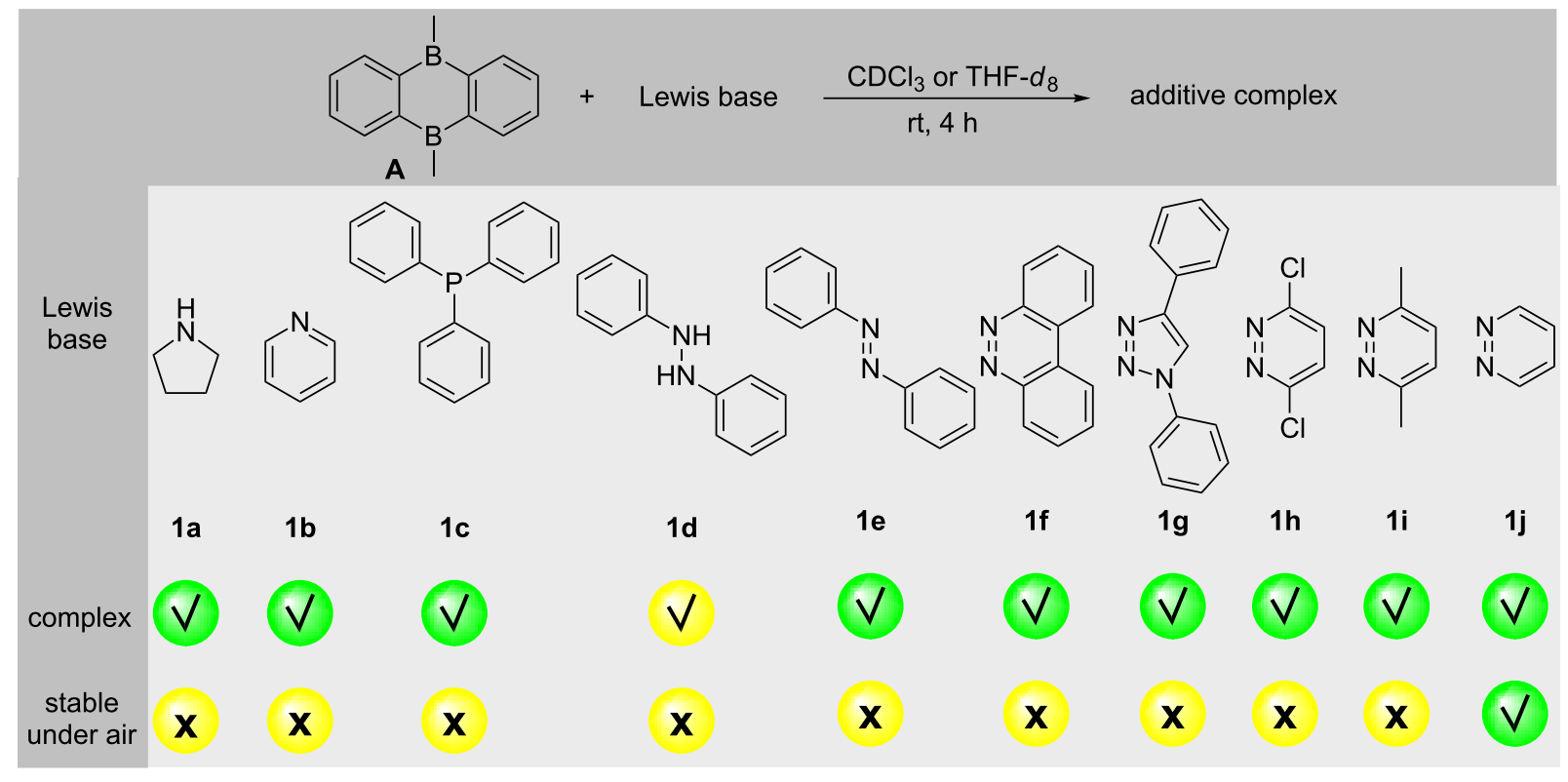

Scheme 2: Complexation reaction of 5,10-dimethyl-5,10-dihydroboranthrene (A) with Lewis bases analyzed by NMR proton spectroscopy. 


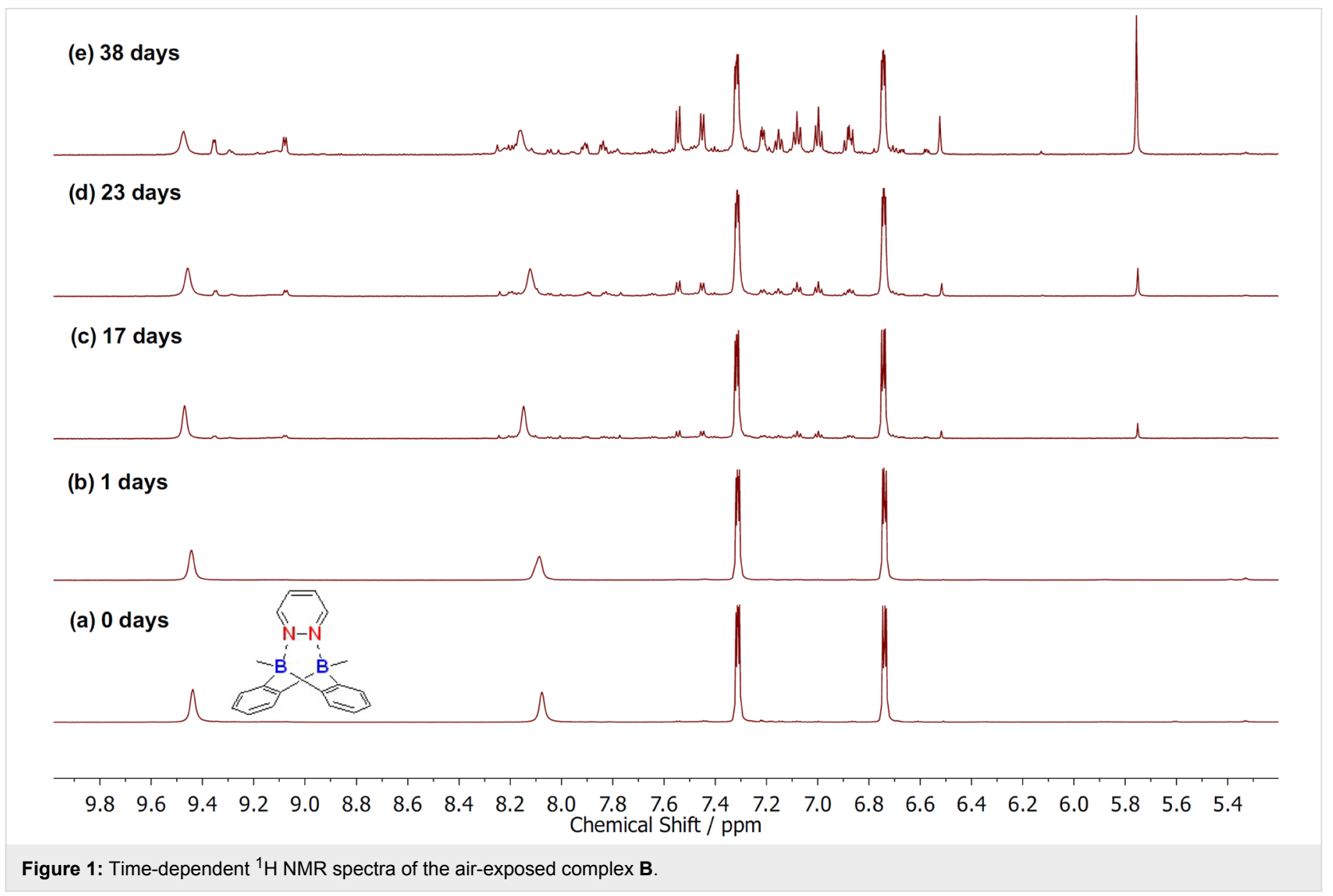

\section{reported procedure}

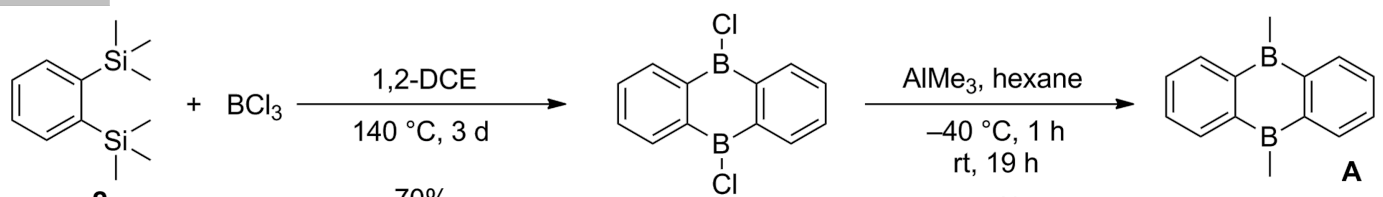


reaction can be carried out in a normal Schlenk tube without any solvent. The methylation reagent, $\mathrm{AlMe}_{3}$ can be added in situ followed by the complexation with pyridazine. The one-pot procedure is also applicable to the synthesis of compound $\mathbf{A}$. In that case, after removal of all the volatile components under reduced pressure, a cooling finger can be installed on the Schlenk tube for sublimation affording compound $\mathbf{A}$ in $55 \%$ overall yield.

\section{X-ray crystal structure analysis}

A single crystal of the air-stable Lewis acid $\mathbf{B}$ was obtained from EtOAc/BrPh 1:1 (v/v). The X-ray analysis revealed a triptycene-type arrangement (Figure 2) which was similar to a pyridazine complex of 9,10-dihydro-9,10-diboraanthracene reported by Wagner and co-workers [19] as well as the phthalazine complex of 5,10-dimethyl-5,10-dihydroboranthrene [17]. The ${ }^{11} \mathrm{~B}$ NMR spectrum of complex $\mathbf{B}$ showed one resonance at $2.4 \mathrm{ppm}$ which also demonstrated the tetra-coordination of boron [20].

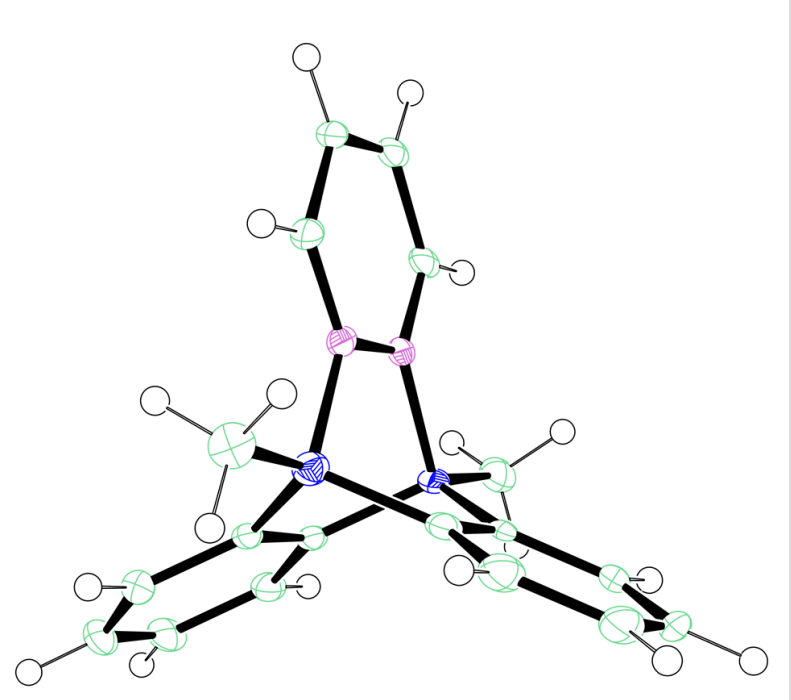

Figure 2: ORTEP drawing (50\% probability) of complex B.

\section{UV-vis spectroscopy analysis}

The absorption properties of the air-stable complex $\mathbf{B}$ was investigated by UV-vis spectroscopy. As shown in Figure 3, there were three absorption bands at $241 \mathrm{~nm}, 279 \mathrm{~nm}, 339 \mathrm{~nm}$, respectively, existing for complex B. A comparison of A with $\mathbf{B}$ revealed that the sharp absorption maximum at $255 \mathrm{~nm}$ of $\mathbf{A}$ underwent a blue shift after coordination with pyridazine, and an additional broad absorption at around $400 \mathrm{~nm}$ appeared.

\section{Catalytic properties}

The application of the air-stable Lewis acid $\mathbf{B}$ for organic synthesis was then tested in several IEDDA reactions of phthal-

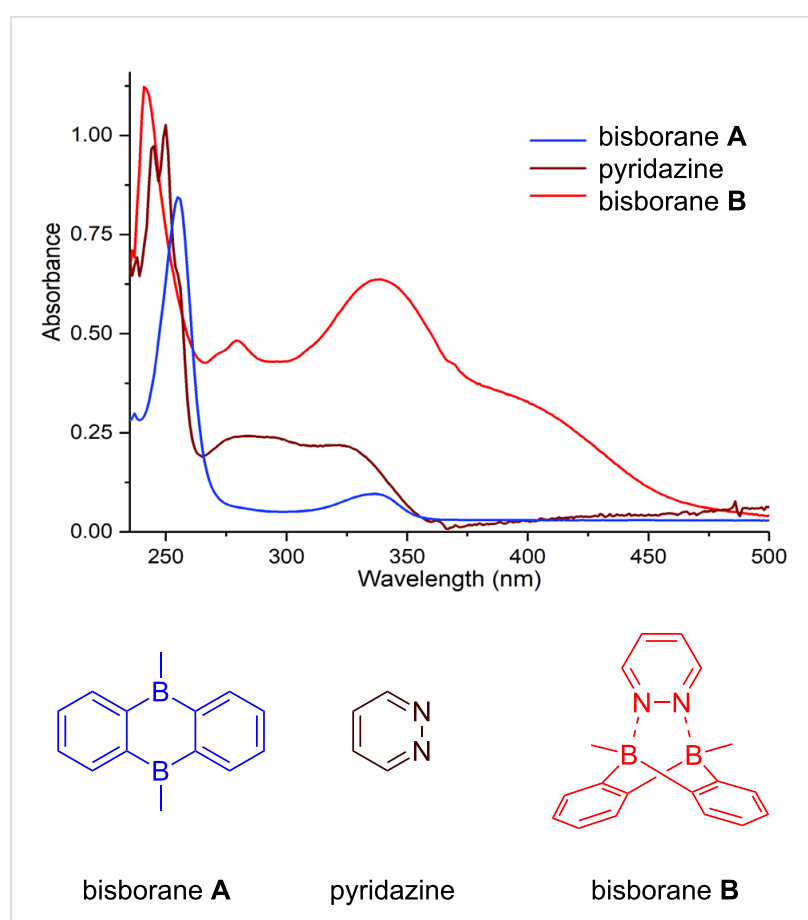

Figure 3: UV-vis spectrum of complex $\mathbf{B}$ was measured in $\mathrm{CHCl}_{3}$ and compared with pyridazine and bisborane $\mathbf{A}$ (concentrations: $\mathbf{B}: 4.52 \times$ $10^{-5} \mathrm{~mol} / \mathrm{L}, \mathbf{A}: 4.52 \times 10^{-5} \mathrm{~mol} / \mathrm{L}$, pyridazine: $\left.3.68 \times 10^{-5} \mathrm{~mol} / \mathrm{L}\right)$.

azine (3) catalyzed by $\mathbf{B}$ or $\mathbf{A}$, respectively. As shown in Table 1, both, dihydrofuran (Table 1, entry 1) and enamines, generated in situ from aldehydes and amines (Table 1, entries 2-4), can take part in the IEDDA reaction. However, the yields were significantly lower in reactions catalyzed with $\mathbf{B}$ when compared to catalyst A (Table 1, entries 1-4). Nonetheless, when a more active dienophile 6-ethoxy-1-methyl-1,2,3,4tetrahydropyridine (4f) was subjected to the IEDDA reaction of phthalazine (3), the yields of the substituted naphthalene 5e were comparable between the two bidentate Lewis acid catalysts (Table 1, entry 5 ). The binding of pyridazine (1j) with bisboron compound $\mathbf{A}$, seems to be too strong to engage a fast ligand exchange with phthalazine (3).

Recently we have demonstrated that catalyst A efficiently promotes the IEDDA reaction of 1,2,4,5-tetrazine (6) with 1,4naphthaquinone (7a) [21]. Therefore, complex $\mathbf{B}$ was also tested as catalyst in the IEDDA reaction of 1,2,4,5-tetrazine (6) with 1,4-naphthaquinonic dienophiles $\mathbf{7 a - 7 d}$. As shown in Table 2, the product 2,3-diaza-9,10-anthraquinone (8a) was obtained in 93\% yield catalyzed by $\mathbf{B}$ while the yield with $\mathbf{A}$ was only $76 \%$ (Table 2, entry 1). Furthermore, the air-stable bisboron complex B successfully catalyzed the reactions and allowed the synthesis of 2,3-diaza-5,12-naphthacenedione (8b), 6-methoxy-2,3diaza-9,10-anthraquinone (8c), and 6,7-dimethoxy-2,3-diaza- 
Table 1: Comparison of different IEDDA reactions of phthalazine (3) catalyzed by bisboron compounds $\mathbf{A}$ and $\mathbf{B}^{\mathrm{a}}$.

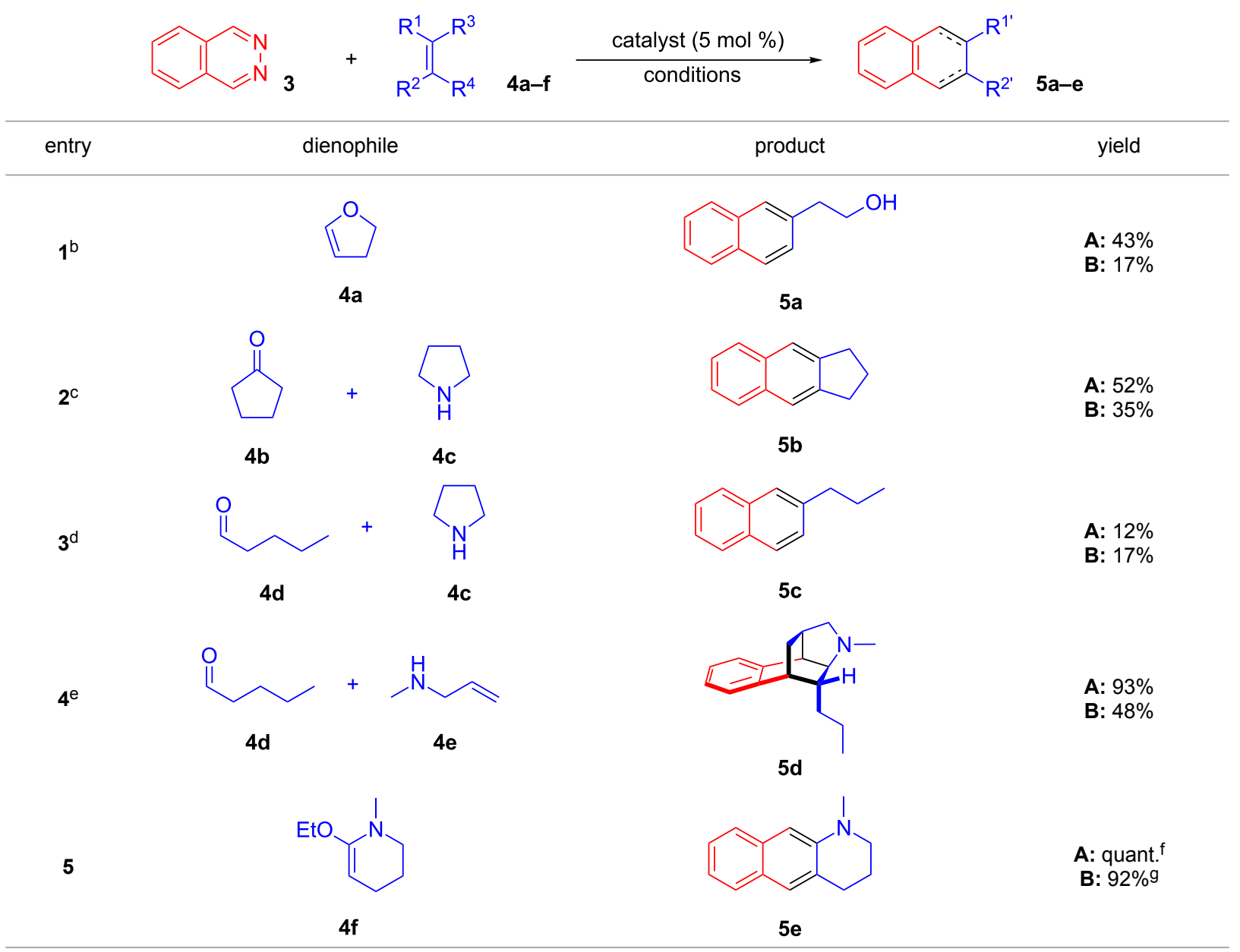

${ }^{a}$ General reaction conditions: phthalazine (1.00 equiv), catalyst $\mathbf{A}$ or $\mathbf{B}$ ( $\left.5 \mathrm{~mol} \%\right)$, dienophile (2.00 equiv; for enamines, generated in situ from aldehyde and amine), solvent (see Supporting Information File 1), and the reaction was carried out under $\mathrm{N}_{2}$ and stirred at given temperature; ${ }^{b}$ diglyme $(0.6 \mathrm{~mL})$, diisopropylethylamine $(200 \mu \mathrm{L}), 170{ }^{\circ} \mathrm{C}, 3 \mathrm{~d}$; ' diglyme $(0.45 \mathrm{~mL}), 55^{\circ} \mathrm{C}, 60 \mathrm{~h}$, work-up with $\mathrm{mCPBA}$; ${ }^{\mathrm{d} T H F}(0.5 \mathrm{~mL}), 60{ }^{\circ} \mathrm{C}, 20 \mathrm{~h}$; e THF (1.5 mL), $60^{\circ} \mathrm{C}, 15 \mathrm{~h}$; diglyme $(1.5 \mathrm{~mL}), 120^{\circ} \mathrm{C}, 2.5 \mathrm{~d}$; ${ }^{\mathrm{g}} \mathrm{CF}_{3} \mathrm{Ph}(1.5 \mathrm{~mL}), 100{ }^{\circ} \mathrm{C}, 19 \mathrm{~h}$.

Table 2: IEDDA reactions of 1,2,4,5-tetrazine catalyzed by bisboron catalysts $\mathbf{A}$ or $\mathbf{B}^{\mathbf{a}}$.

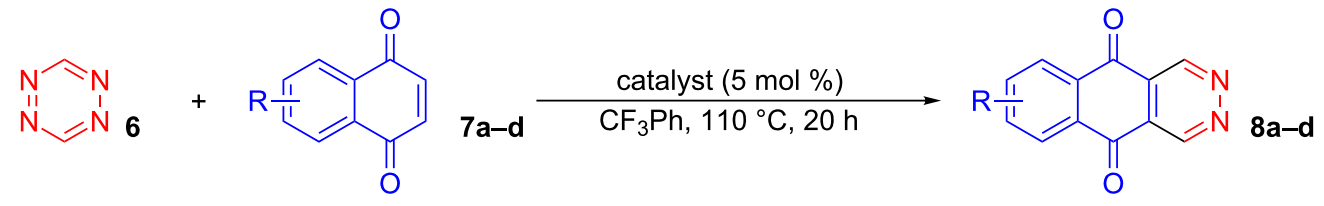

entry


Table 2: IEDDA reactions of 1,2,4,5-tetrazine catalyzed by bisboron catalysts $\mathbf{A}$ or $\mathbf{B}^{\mathbf{a}}$. (continued)

2<smiles>O=C1C=CC(=O)c2cc3ccccc3cc21</smiles>

$7 b$<smiles>COc1ccc2c(c1)C(=O)C=CC2=O</smiles>

7c<smiles>COc1cc2c(cc1OC)C(=O)C=CC2=O</smiles>

7d<smiles>O=C1c2cnncc2C(=O)c2cc3ccccc3cc21</smiles>

$8 b$<smiles>COc1ccc2c(c1)C(=O)c1cnncc1C2=O</smiles>

$8 c$<smiles>COc1cc2c(cc1OC)C(=O)c1cnncc1C2=O</smiles>

8d

a General reaction conditions: 1,4-naphthoquinone (1.00 equiv), catalyst $\mathbf{A}$ or $\mathbf{B}$ (5.00 mol \%), 1,2,4,5-tetrazine (5.00 equiv) in $\mathrm{CF}_{3} \mathrm{Ph}$ (see Supporting Information File 1) was heated at $110^{\circ} \mathrm{C}$ for $20 \mathrm{~h}$ under $\mathrm{N}_{2}$.

9,10-anthraquinone (8d) in excellent yields $(82 \%, 88 \%, 95 \%$, respectively) supporting the practicality of this catalyst for IEDDA reactions (Table 2, entry 2-4).

\section{Conclusion}

In summary, we report an air-stable bidentate Lewis acid bisboron complex as an efficient catalyst for IEDDA reaction of 1,2-diazine as well as 1,2,4,5-tetrazine. Its stability towards air and moisture was demonstrated by NMR analysis and enables its application in organic synthesis without using a glovebox. A new one-pot procedure for its synthesis was developed starting from 1,2-bis(trimethylsilyl)benzene, which will greatly enhance its practicality. X-ray crystal structure analysis and $\mathrm{UV}$-vis spectroscopy analysis were conducted. The tetra-coordination of the boron atoms and the highly symmetric molecular framework help to stabilize the adduct complex with respect to oxidation or hydrolysis. In addition comparative reactions were carried out and the results showed that the catalytic activity of the complex in IEDDA reactions depended on its performance in ligand exchange with the diazine substrates.

\section{Experimental}

Complexation of 5,10-dimethyl-5,10-dihydroboranthrene with Lewis bases: In the glovebox, 5,10-dimethyl-5,10-dihydroboranthrene (A, $8.0 \mathrm{mg}, 0.0392 \mathrm{mmol}, 1.00$ equiv) and Lewis base (for monodentate: $0.0784 \mathrm{mmol}, 2.00$ equiv; for bidentate: $0.0392 \mathrm{mmol}, 1.00$ equiv) were dissolved in $0.5 \mathrm{~mL}$ $\mathrm{CDCl}_{3}$ in an NMR tube (in case of 3,6-dimethylpyridazine,
THF- $d_{8}$ was used as solvent). The NMR tube was sealed and kept for $4 \mathrm{~h}$ and then monitored by ${ }^{1} \mathrm{H}$ NMR spectroscopy.

One-pot synthetic procedure of the bisboron-pyridazine complex B: A Schlenk tube was charged with 1,2-bis(trimethylsilyl)benzene ( $1.78 \mathrm{~g}, 8.00 \mathrm{mmol}, 1.00$ equiv) and a stirring bar. Then, boron tribromide $(4.21 \mathrm{~g}, 1.7 \mathrm{~mL}, 16.8 \mathrm{mmol}$, 2.10 equiv) was added slowly under $\mathrm{N}_{2}$ while stirring the reaction mixture. Afterward, the reaction mixture was stirred for $1 \mathrm{~h}$ at $\mathrm{rt}$ and stirring was continued at $140{ }^{\circ} \mathrm{C}$ for $2 \mathrm{~d}$. After cooling the reaction mixture to $\mathrm{rt}$, the excess boron tribromide was removed under reduced pressure connected to a cold trap. The Schlenk tube was filled again with $\mathrm{N}_{2}$ and $n$-hexane (degassed, $15.0 \mathrm{~mL}$ ) was added. The tube was then placed in an ice bath to precipitate the intermediate product. The liquid was removed by a syringe under $\mathrm{N}_{2}$ to afford a pale brown solid. Then, the residue was washed with degassed $n$-hexane $(2 \times 10.0 \mathrm{~mL})$ under $\mathrm{N}_{2}$. Additional $n$-hexane (degassed, $10.0 \mathrm{~mL}$ ) was added and the mixture was stirred at $0{ }^{\circ} \mathrm{C}$ for several minutes. Then, trimethylaluminum $(4.0 \mathrm{~mL}, 2.0 \mathrm{M}$ in $n$-hexane, $8.00 \mathrm{mmol}$, 1.00 equiv) was added under $\mathrm{N}_{2}$. After $1 \mathrm{~h}$, the reaction mixture was warmed to $\mathrm{rt}$ and then stirred for an additional $1 \mathrm{~h}$. The volatile components of the reaction mixture were removed under reduced pressure connected to a cold trap. To the residue was then added $\mathrm{CH}_{2} \mathrm{Cl}_{2}$ (degassed, $10.0 \mathrm{~mL}$ ) followed by pyridazine (320 mg, $4.00 \mathrm{mmol}, 0.500$ equiv) under $\mathrm{N}_{2}$. After $3 \mathrm{~h}$ of stirring, the reaction mixture was filtrated with a Büchner funnel and the solid was washed with DCM twice to afford a yellow solid ( $581 \mathrm{mg}, 51 \%$ yield, purity: $85 \%$ calculated based 
on ${ }^{1} \mathrm{H}$ NMR). [Column chromatography on silica gel (EtOAc/ cyclohexane $4: 1$ ) yielded pure product as an orange solid with a decreased yield (284 mg, 25\% yield)]. ${ }^{1} \mathrm{H}$ NMR (400 MHz, THF- $\left.d_{8}\right) \delta 9.26$ (br s, 2H), 7.69 (br s, 2H), 7.28 (dd, ${ }^{3} J=5.2$ $\mathrm{Hz}, 3.2 \mathrm{~Hz}, 4 \mathrm{H}), 6.71\left(\mathrm{dd},{ }^{3} J=5.2 \mathrm{~Hz}, 3.2 \mathrm{~Hz}, 4 \mathrm{H}\right), 0.95$ (s, $6 \mathrm{H}) ;{ }^{13} \mathrm{C}$ NMR $\left(100 \mathrm{MHz}, \mathrm{THF}-d_{8}\right) \delta 147.2,133.7,128.1$, 124.2 ( $\mathrm{C}$ atoms next to boron are not observable due to quadrupole coupling); ${ }^{11} \mathrm{~B}$ NMR (128 MHz, THF- $\left.d_{8}\right) \delta 2.4(\mathrm{~s}) \mathrm{M}$; mp 252-253 ${ }^{\circ} \mathrm{C}$; HRMS-ESI $(\mathrm{m} / \mathrm{z}):[\mathrm{M}+\mathrm{Na}]^{+}$calcd for $\mathrm{C}_{18} \mathrm{H}_{18} \mathrm{~B}_{2} \mathrm{~N}_{2}$, 307.1548; found, 307.1561; IR (neat): 3124 , 3041, 2965, 2918, 2829, 1581, 1468, 1425, 1310, 1286, 1276, $1153,1113,997,950,889,754,713,610,575$.

\section{IEDDA reactions catalyzed by the air-stable bidentate Lewis acid catalyst $B$} General procedure A for IEDDA reactions of phthalazine: In a Schlenk tube charged with a stirring bar, the air-stable bidentate Lewis acid catalyst B (5.00 mol \%) and the stated solvent were added under $\mathrm{N}_{2}$. Then, the phthalazine (1.00 equiv), dienophile (2.00 equiv; for enamines, generated in situ from aldehyde and amine) were added subsequently. The reaction mixture was stirred at the given temperature. After the reaction was finished, the solvent was removed. The remaining residue was purified by flash column chromatography over $\mathrm{SiO}_{2}$ to obtain the product.

General procedure $B$ for IEDDA reactions of 1,2,4,5tetrazine: The air-stable bidentate Lewis acid catalyst $\mathbf{B}$ ( $25.0 \mu \mathrm{mol}, 5.00 \mathrm{~mol} \%$ ) and 1,2,4,5-tetrazine (5.00 equiv) in $\mathrm{CF}_{3} \mathrm{Ph}(2.5 \mathrm{~mL})$ were thoroughly stirred for several minutes. Then, 1,4-naphthoquinone (1.00 equiv) was added, the reaction mixture was heated at $110{ }^{\circ} \mathrm{C}$ for $20 \mathrm{~h}$. The solvent, together with the excess of 1,2,4,5-tetrazine were distilled off from the resulting mixture in vacuo. The residue was purified by column chromatography over $\mathrm{SiO}_{2}$ (ethyl acetate/cyclohexane 1:1) to obtain the product.

\section{Supporting Information}

\section{Supporting Information File 1}

Detailed experimental procedures, copies of ${ }^{1} \mathrm{H}$ and

${ }^{13} \mathrm{C}$ NMR spectra, UV-vis spectra as well as the X-ray crystallography.

[https://www.beilstein-journals.org/bjoc/content/ supplementary/1860-5397-14-48-S1.pdf]

\section{Supporting Information File 2}

CIF of bisborane complex $\mathbf{B}$.

[https://www.beilstein-journals.org/bjoc/content/ supplementary/1860-5397-14-48-S2.cif]

\section{Acknowledgements}

Funding by the BMEL (Federal Ministry of Food and Agriculture) within the project FOREST (22403116) and by the CMBlu AG for Dr. Longcheng Hong is acknowledged. We also thank Dr. Heike Hausmann, Institute of Organic Chemistry, Justus Liebig University, for NMR spectroscopy measurements.

\section{ORCID ${ }^{\circledR}$ iDs}

Longcheng Hong - https://orcid.org/0000-0003-2268-8304 Andreas H. Heindl - https://orcid.org/0000-0002-5403-2177 Hermann A. Wegner - https://orcid.org/0000-0001-7260-6018

\section{References}

1. Png, Z. M.; Zeng, H.; Ye, Q.; Xu, J. Chem. -Asian J. 2017, 12, 2142-2159. doi:10.1002/asia.201700442

2. Li, J.-L.; Liu, T.-Y.; Chen, Y.-C. Acc. Chem. Res. 2012, 45, 1491-1500. doi:10.1021/ar3000822

3. Yang, K.; Dang, Q.; Cai, P.-J.; Gao, Y.; Yu, Z.-X.; Bai, X. J. Org. Chem. 2017, 82, 2336-2344. doi:10.1021/acs.joc.6b02570

4. Eschenbrenner-Lux, V.; Küchler, P.; Ziegler, S.; Kumar, K.; Waldmann, H. Angew. Chem., Int. Ed. 2014, 53, 2134-2137. doi:10.1002/anie.201309022

5. Esquivias, J.; Arrayás, R. G.; Carretero, J. C. J. Am. Chem. Soc. 2007, 129, 1480-1481. doi:10.1021/ja0658766

6. Esquivias, J.; Alonso, I.; Arrayás, R. G.; Carretero, J. C. Synthesis 2009, 113-126. doi:10.1055/s-0028-1083276

7. Sundararajan, G.; Prabagaran, N.; Varghese, B. Org. Lett. 2001, 3, 1973-1976. doi:10.1021/ol0159221

8. Anderson, E. D.; Boger, D. L. J. Am. Chem. Soc. 2011, 133, 12285-12292. doi:10.1021/ja204856a

9. Gruseck, U.; Heuschmann, M. Tetrahedron Lett. 1987, 28, 6027-6030. doi:10.1016/S0040-4039(00)96855-2

10. Boger, D. L.; Coleman, R. S. J. Am. Chem. Soc. 1987, 109, 2717-2727. doi:10.1021/ja00243a027

11. Wilkie, G. D.; Elliott, G. I.; Blagg, B. S. J.; Wolkenberg, S. E.; Soenen, D. R.; Miller, M. M.; Pollack, S.; Boger, D. L. J. Am. Chem. Soc. 2002, 124, 11292-11294. doi:10.1021/ja027533n

12. Bodwell, G. J.; Li, J. Angew. Chem., Int. Ed. 2002, 41, 3261-3262. doi:10.1002/1521-3773(20020902)41:17<3261::AID-ANIE3261>3.0.CO ;2-K

13. Kessler, S. N.; Wegner, H. A. Org. Lett. 2010, 12, 4062-4065. doi:10.1021/ol101701z

14. Schweighauser, L.; Wegner, H. A. Chem. - Eur. J. 2016, 22, 14094-14103. doi:10.1002/chem.201602231

15. Kessler, S. N.; Neuburger, M.; Wegner, H. A. J. Am. Chem. Soc. 2012, 134, 17885-17888. doi:10.1021/ja308858y

16. Schweighauser, L.; Bodoky, I.; Kessler, S. N.; Häussinger, D.; Donsbach, C.; Wegner, H. A. Org. Lett. 2016, 18, 1330-1333. doi:10.1021/acs.orglett.6b00276

17. Kessler, S. N.; Neuburger, M.; Wegner, H. A. Eur. J. Org. Chem. 2011, 3238-3245. doi:10.1002/ejoc.201100335

18. Bieller, S.; Zhang, F.; Bolte, M.; Bats, J. W.; Lerner, H.-W.; Wagner, M. Organometallics 2004, 23, 2107-2113. doi:10.1021/om049954e

19. Lorbach, A.; Bolte, M.; Lerner, H.-W.; Wagner, M. Chem. Commun. 2010, 46, 3592-3594. doi:10.1039/c001803a 
20. Nöth, H.; Wrackmeyer, B. Nuclear Magnetic Resonance Spectroscopy of Boron Compounds. In NMR Basic Principles and Progress; Diehl, P.; Fluck, E.; Kosfeld, R., Eds.; Springer Verlag: Berlin, 1978. doi:10.1007/978-3-642-66757-2

21. Hong, L.; Ahles, S.; Strauss, M. A.; Logemann, C.; Wegner, H. A Org. Chem. Front. 2017, 4, 871-875. doi:10.1039/C7Q000172J

\section{License and Terms}

This is an Open Access article under the terms of the Creative Commons Attribution License

(http://creativecommons.org/licenses/by/4.0), which permits unrestricted use, distribution, and reproduction in any medium, provided the original work is properly cited.

The license is subject to the Beilstein Journal of Organic Chemistry terms and conditions:

(https://www.beilstein-journals.org/bjoc)

The definitive version of this article is the electronic one which can be found at: doi:10.3762/bjoc. 14.48 